\title{
My story in response to the stories of my patients' experience of the impact of the COVID-19 pandemic: a relational psychoanalytic approach
}

\author{
Zelda Gillian Knight \\ Department of Psychology, Faculty of Humanities, Auckland Park Campus, University of Johannesburg, Johannesburg, South Africa
}

\begin{abstract}
The hallmark of being human is to tell stories. The stories told give meaning to the experience, and it is in telling stories about our experience, that we begin the process of meaning-making. Psychotherapy is storytelling, and in our consultation room we, as psychotherapists, listen to the tales told. This paper documents my story in response to some of the stories of my patients' experience of the impact of the unprecedented impact of the coronavirus disease 2019 (COVID-19) pandemic. While there have been pandemics before, this pandemic is arguable unique because of social media and the number of people across the world who can share their experience. It is said that more than 4 billion people have self-isolated at home together at the same time as a collective humanity in response to their country's lockdown rules. For psychotherapists, the shift to online therapy has allowed for a continuation of psychotherapy, and the telling of stories of COVID-19. Some of their stories are sad stories of loss and uncertainty. Some of their stories are more positive and inspiring. In this paper, three patients' stories have been selected that illustrate both the positive and negative reactions to the COVID-19 pandemic. As the conceptual framework is relational psychoanalytic with its focus on the dynamics of the intersubjective relationship, my story, as counter-transference reactions are incorporated.
\end{abstract}

Key words: COVID-19; psychotherapy; story; counter-transference; intersubjectivity.

\section{Introduction}

With the advent of the coronavirus disease 2019 (COVID-19) pandemic, my patients tell me stories of their experiences of this pandemic. Some of their stories about COVID-19 are stories of distress, rooted in loss and uncertainty. Some of their stories are more uplifting

Correspondence: Zelda Gillian Knight, Department of Psychology, Faculty of Humanities, Auckland Park Campus, University of Johannesburg, Johannesburg, South Africa.

Tel.: +27.83.311.3229.

E-mail: zknight@uj.ac.za

Citation: Knight, Z. G. (2020). My story in response to the stories of my patients' experience of the impact of the COVID-19 pandemic: a relational psychoanalytic approach. Research in Psychotherapy: Psychopathology, Process and Outcome, 23(3), 291-297. doi: 10.4081/ripppo.2020.490

Received for publication: 30 August 2020.

Revision received: 3 November 2020.

Accepted for publication: 14 November 2020.

This work is licensed under a Creative Commons Attribution NonCommercial 4.0 License (CC BY-NC 4.0).

${ }^{\circ}$ Copyright: the Author(s), 2020

Licensee PAGEPress, Italy

Research in Psychotherapy:

Psychopathology, Process and Outcome 2020; 23:291-297

doi:10.4081/ripppo.2020.490 and positive. The hallmark of being human is the desire to tell and hear stories. For centuries in all cultures, stories told and stories heard have defined us both personally and culturally, drawing us into a family, a clan, a tribe, a nation, and a collective as a human species. As psychotherapists, we hear them, and this act of listening begins to give their stories some grounding and validation. It is largely in telling the story to another that patients can begin to make sense of their experience. In a way psychotherapy is a process of storytelling. Our work is to be empathically immersed in their stories. We are thus trained to bear witness to their stories, absorb them, and to also protect ourselves from some the details of the stories that could unsettle us too much, and make our work less effective. In this regard, we also have our own inner stories that we bring into the therapeutic process of 'being with' the other, and then, our inner stories are subsequently shaped and formed by and through their stories, such is the nature of the psychodynamics of transference and counter-transference that make up our joint intersubjectivity. In my experience as a psychotherapist, the essential story told by patients of the COVID19 pandemic is the story of life as no longer being the same. They describe it as the new normal. This new way of being and relating may include challenges of living under lockdown rules, such as the unexpected loss of income, loss of physical connection with significant others, being confined to the home, unplanned shifts to online work, as well as coping with wearing a mask. It is thus the story that has forced many patients (and therapists) into re-evaluating what is important in life. 


\section{What this paper is about}

This paper documents my story in response to some of the stories of my patients' experience of the impact of the COVID-19 pandemic. While there have been pandemics recorded in history before, such as the Spanish flu that killed 50 million people, this pandemic is arguable unique because of social media. Social media has given people an opportunity to share their experience, and such experience is shared across space and time, uniting and bonding people in a collective community of telling the tale of COVID-19. It is reported that more than 4 billion people have self-isolated at home, something unprecedented. In the consultation room, now a virtual space for many therapists, patients tell their stories of the experience of the impact of COVID-19. Some of their stories describe difficult experiences of loss and uncertainty. Some of their stories are more uplifting and positive. In this paper, three patients' stories have been selected that illustrate both the positive and negative experiences of the impact of the COVID-19 pandemic. As the paper focuses on the intersubjective nature of the therapeutic relationship, my counter-transference, as a storied reaction, is included throughout.

\section{A brief note on counter-transference within relational psychoanalytic work}

Since the theoretical relational turn in psychoanalytic theory and psychotherapy (Aron, 1996; Atlas \& Aron, 2018; Mitchell, 2000) there has been an emphasis on the value of not only the awareness of the analyst's reactions, or counter-transference, towards the patient (Benjamin, 2009; Cooper, 2012) but also on how such reactions can be used to inform the therapist about the patient and their dynamics and process. With this relational turn, there is now a view of two subjectivities relating to each other in the therapeutic process. The implication of this two-person approach is the understanding that the analytic material that arises in the therapy process is assumed to be a co-creation of the internal dynamics of both the analyst's and the patient's subjectivity (Aron, 1996; Parsons, 2006) such that there is a flow and ebb of the subjectivity of the one with the other, leading to a dance of intersubjectivity occurring in the room. This joint consciousness, or intersubjectivity, between the two members of the dyad is thus understood as a bi-directional engagement between patient and analyst such that each person registers differently - a co-created and mutual dance governed by what is recognized as the concept of the analytic third (Ogden, 1994). Application to relational psychoanalytic work of this idea of two subjectivities in the room, or the two-person approach to therapy (Aron, 1996) means that countertransference becomes a rich source of deepening our understanding of what the patient thinks, wants, and feels about themselves, others, and us as therapists. It is also viewed as a rich source of self-knowledge for therapists in that our patients evoke feelings and perceptions within us that also need reflection and examination in service of the patient who sits before us. In relational thinking, an important sign of thirdness is being open to hear multiple voices - "I can hear both your voice and mine as can you without one cancelling the other out; I can hear more than one part of yourself, you can hear more than one part of yourself ... It is now possible to recognize the presence of multiple voices and parts of self" (Benjamin, 2009, p. 442). Later, Benjamin (2018) wrote further about intersubjectivity (transference and counter-transference) within the therapeutic relationship to emphasize how: 'I change you, you change me', meaning that the paradox is that both participants are themselves changed by the other. This idea of intersubjectivity and co-creation of the analytic material means that my reactions to my patients' stories shape and change my own inner stories about them but also about myself, thus multiple voices are heard, and made sense of, within the intersubjective milieu. Once this listening to multiples voices unfolds, the significance of empathy becomes paramount so as to make and maintain a connection with our patients (Geist, 2013).

\section{My story in response to the stories of my patients' experience of the impact of the COVID-19 pandemic}

My own story begins when lockdown was enforced seven months ago in March 2020 as a result of the COVID-19 pandemic. Now, in early November 2020, we are still in continuous lockdown. Given this length, we are possibly the world longest and uninterrupted period of lockdown, and perhaps for months, the strictest lockdown. In Johannesburg where I practice as a psychoanalytically-informed psychotherapist, we underwent nine weeks of what can be termed 'hard lockdown' which had rules and regulations that severely limited freedom of movement, the closures of non-essential businesses. Schools were closed, and five months later, most children were not at school. Hard lockdown was difficult to bear for many of my patients, giving rise to anxiety and depression. The months of hard lockdown lead to some restrictions being eased a bit to allow more economic activity and freedom of movement.

For the first five months of lockdown, unique perhaps to this country, no family visits were permitted, and a ban on alcohol and cigarettes was implemented with the threat of imprisonment and a criminal record for any infringement. The ban on family visits hit my patients the hardest. Some were unable to abide by this rule, and sneaked out under the threat of arrest, to visit parents and children in the same city. Also unique to this country was a nighttime curfew, still enforce, and the public control by police and army to enforce the lockdown rules. Many arrests 
were made, including wedding and funeral parties as there was a ban on gatherings of more than 50 people.

One major impact of the COVID-19 pandemic on both myself and my patients has been the unplanned shift to online therapy. In the beginning of lockdown, as social isolating and social distancing was enforced, it became apparent that the only way to continue therapy under these conditions was to shift to online psychotherapy ${ }^{1}$. In the past I had not used the Internet for therapy. I needed to rapidly self-educate on becoming adapt with all e-platforms. It was stressful for me. At the time of the shift to online therapy, I wondered if my current patients would join in with this new virtual modality, or if new patients would come on board with this kind of online work. I also wondered if my Wi Fi would be strong and stable enough to manage video calls to my patients. My current patients, however, did join me for online therapy, and we continued, with mostly little internet problems, for many months during lockdown. I also had new appointments.

Below are some of the stories of my patients of lockdown and the impact of the COVID-19 pandemic.

\section{The more inspiring stories}

Aaron $^{2}$, was a mature, energetic and healthy Jewish man in his late $50 \mathrm{~s}$ who had been seeing me before lockdown and the outbreak of COVID-19 pandemic for help with the dissolution of his 28-year marriage. He was a likeable, thoughtful and quiet man, thinking about things in a deep and meaningful way. While he was now living alone, his adult children living in another city, he found that life under lockdown allowed him to explore his world more because lockdown initially had rules against visiting family and friends. This ruling allowed him to spend time alone, which he loved. He reported that the isolation was experienced as healing. There were now no expectations from others, including family, and he could live in peace, contemplating each new day, each new moment. He became mindful of his thoughts, of his emotions, and of his breath. He decided to begin to write short stories, always wanting to have done this kind of work years before. Later as lockdown continued and there were longer periods of self-isolating, Aaron found himself starting online yoga, something he could not do before because he was busy with meeting expectations of others. He had retired at 55 years from a successful business, and now he was trying to find a new purpose in life. When the divorce occurred, he reported that it set him free. Free to find himself, or find parts of himself hidden by years of social compliance,

\footnotetext{
Online psychotherapy, referred to as online therapy, is a psychotherapeutic intervention that makes use of the Internet and its various eplatforms, such as Skype, Zoom, MS Teams, WhatsApp, to connect mental health professionals with their patients or patients.

The name Aaron and all other names of patients' are pseudonyms. Any other identifying data related to them have been changed so as to protect their identity.
}

meeting expectations, and a marriage that he felt controlled him.

I always enjoyed our sessions. Aaron would speak for a long time and I did not intrude. He spoke slowly and with care, selecting his words as he may have done with his new adventures into writing stories. I felt as if I was witnessing the unfolding of a flower that had remained as a bud for too long. He reported that the COVID-19 pandemic was about a call or calling for a new collective consciousness that was concerned more with inner life than outer materialistic trappings and wealth creation. He said he spent more time in the garden, listening to the sound of life, from children laughing next door, to birds singing, to the constant roar of traffic on a nearby highway. The global pandemic initiated an inner process of self-discovery as he began to think about life as being one of freedom and possibilities. He reported that he was not afraid of dying from the virus, and that he did not change his views of death as final, with no afterlife. In fact, he reported a sense of being happy for the first time in years. He did not want lockdown to end in that it might mean he would have to make contact again with friends and family. He wanted the isolation that lockdown enforced.

Aaron's response to the COVID-19 pandemic and the resultant lockdown was unusual and refreshing. I had not heard many similar stories from my other patients. I was most affected by Aaron in his storytelling because he was so positive in his approach to his own new world of selfisolating. It resonated with me. For some months I had also begun to find a lost part of me that can be described as a return to my center. In the businesses of life prior to lockdown, I had lost something of myself in my treadmill pressure to perform, to meet expectations, to fall in line with a social world of demands. Aaron's idea of a call to a new consciousness made sense to me and I also began to re-think what I did. Because so much of those early lockdown days required home life and self-isolation, I found myself also enjoying the pleasure of being at home. While not alone at home, and not afraid of contracting the virus, perhaps because I felt I would recover, my thoughts shifted to what I used to like doing, and what gave me a sense of inner peace, and thus to find ways to escape from the hurriedness of city life. My life, like Aaron, became more free as I unshackled the need to always be there for others, to live up to expectations, of performing well, and to self-care more. Aaron once said, "I am finding freedom in doing stuff I would not have done before because it would not have been socially acceptable". He reported that he had stopped shaving his face, and now he was growing a beard. His ex-wife always said men with beards were not to be trusted, and this had negatively impacted on him and stayed with him. Now he flaunted his beard whenever his ex-wife contacted him on Zoom. He also said that the isolation of lockdown allowed him to experiment with new styles of clothing. He started wearing loose shirts untucked into pants. His ex-wife had said that 
one can judge a good man by how he tucks his shirt into his pants.

In response to his stories of finding freedom, I think that I also began to do things that I had not done before. I stopped shaving my legs. Hairy legs are something not approved by our society for a westernized woman. Like his beard and untucked shirt, I felt inspired by his stories of finding freedom and going against what is socially expected. With the stories of finding himself, of becoming a different person, of welcoming and wanting lockdown to last as it cocooned him with new pleasures in freedoms unexplored and unexperienced, Aaron's stories impacted me in a positive and profound way. While other patients told stories of fear and distress, he told stories of returning to himself under lockdown. I found myself being more free within myself too. When restrictions lessened, I bought new non-western clothing that reflected my new inner freer self. Like Aaron, I resonated with his idea that the COVID-19 pandemic was a call to a new consciousness that sought inner freedoms once lost and unclaimed.

\section{Comment on the more inspiring stories}

Psychotherapy is storytelling. Most of the time the stories are distressing. While Aaron had stories of distress, his experience was also stories of growth and self-discovery. "The consulting room of the psychotherapist is a powerful sanctuary for storytelling and an important laboratory for learning about this relationship between story and transformation" (Abbot, 2011, p. 94). Added to this is the notion that it is in telling the story that healing happens. The story needs to be told to release it from the shackles of repetition and internalization that seek to dominate every new moment and every new experience. Healing and transformation, once the story is told, takes on many forms and shapes, but for Aaron he began to discover something hidden within himself - the capacity for renewal and regeneration.

As stories are told in therapy of the COVID-19 pandemic, we need to ask ourselves as therapists what story could be told to the patient in response to their stories to facilitate understanding and further storytelling. This is the work of empathy, as so eloquently described by Kohut (1959) who elevated it to being the core of therapeutic work. As therapists we hear the stories of our patients. In response, our own inner stories are evoked and rise up into consciousness so that the relationship is imbued with our stories too. Suddenly there are two layers of storytelling mirrored by the two people in the therapy. My own counter-transference to Aaron stories is irrevocably inserted into his stories in such a way that I hear his stories against this background music of my own storied responses. I found my story of COVID-19 called me to a new awakening about finding a new story for myself, a new storied self. Inspired by Aaron, I reached beyond the strain and stress of living under lockdown, and the darkening shadows of angst and fear of an uncertain future. I found something different, a new story for myself about perseverance and human dignity. As I continued to selfisolate into a fifth month of lockdown, with a loss of physical contact with colleagues, friends and family, my story shifted to it is good enough. In the past and prior to lockdown, I was a driven person, ambitious and overly selfdemanding. Now with lockdown, there is a new normal and with this, there is a sense that 'things I do are good enough' thus releasing me, somewhat, from my own inner stories of high expectations and demands. This is the impact on me of the good stories of my patients of COVID19 pandemic.

\section{The stories that describe difficult experiences of the impact of COVID-19}

Katlego was a married African woman in her early 40s who made an appointment at the start of lockdown because her husband, Tshepo, has tested positive for COVID-19. They had been married for a few years and she had just given birth to their third child. She described their marriage as warm and supportive. Due to lockdown rules, her older two children were now no longer at school and doing online learning from home. Katlego was not permitted to go to the office as she was not an essential worker. She made a plan to work online from home. Her husband, Tshepo, was a medical doctor and had contracted the coronavirus at work. He was a first responder to people being admitted to hospital with COVID-19. Tshepo was in his late 40s, and was a diabetic with a congenital heart problem, which was rectified several years ago with open heart surgery. Within two days of contracting the virus, Tshepo was seriously ill with difficulties breathing and admitted to hospital. With a new baby and two young children to care for as well as a full-time job, and no family or domestic help, Katlego was overwhelmed. In addition, she reported that her elderly parents, who were living across the city, could not visit her, nor could she see them to assist them with daily necessities, such as grocery shopping.

In our first session, as Tshepo lay in hospital struggling to breath, Katlego described her angst and fear of losing him. She said how frightened she was of being left alone to cope if he should pass away. We talked about her fear of losing him as well as a past memory of being a small child and left at home in the evenings while her religious parents went to bible study. While the high demands of her life were mentioned in passing, I noted that she had an intense anxiety about being abandoned. She told me other stories that had themes of being left alone or left behind. One story was about how her father forgot to collect her from school one afternoon and she waited until dark before he finally came. She reported how she had a fear of the dark and that she could not easily trust anyone to be there for her. These stories set the scene of me to be alerted to the possibility that she may not trust me to be there for her, or that I must not let her down or leave her. 
In our second session, Katlego spoke again about her fear of losing Tshepo. During this time, as lockdown rules did not permit visits to family, she could not visit Tshepo in hospital. This was devastating for her. We worked with this experience in therapy and it seemed to echo earlier stories of being left alone. Later in the same session, she spoke about her own fear of dying from the virus. She became upset when she told me that she would call the hospital each day for a report on her husband, only to be told that he was not any better. With memories of abandonment and a fear of loss as well as the ongoing stress of living under lockdown, Katlego was becoming more anxious. I suggested increased therapy sessions as well as recommended medication for anxiety. She agreed to both. In our third session, a few days after Tshepo was admitted to hospital, she came to therapy in a state of distress. Tshepo had passed away the previous night from COVID-19. She was not there to be with him because of the ruling of lockdown about family visits. She told me the story that she had received a call in the night from the hospital, and was informed about his death. He had been put on a ventilator late the same night but this had not helped him. Now she 'sat across from me' on our online video call, with tears streaming down her face. She was utterly devastated and inconsolable. Her world had been shattered. We did a long marathon session that day in which she mostly cried and asked me what was she supposed to do now. It was an emotionally intense session. I felt my own heart break for her. Indeed, what was she supposed to do now?

I had not known anyone die from COVID-19, not then, and not now. In the first five months as the virus peaked in the winter months and over 640000 people were infected, I was aware of only two colleagues who had contracted the disease but both had fully recovered. Katlego's story was heart-breaking because she was now a single mother, dealing with the cycles of grief and pain regarding the death of Tshepo, and essentially alone. Her story had a profound impact on me because I came to be reminded of the fragility of life. I could not possibly know the depth of her pain and loss because I was living under lockdown with very different circumstances which were essentially comfortable, supportive, and thus enjoyable. While I could empathize with her, I felt that her world was broken. She described feeling lost and without a sense of what to do. In subsequent sessions, she explored her grief and loss, and each time we met, she slowly began to make sense of what had happened. She often returned to her stories of childhood abandonment and linked that feeling with what was happening now. My own story shifted because of her story. I had an encounter with death and pain as never before in terms of this pandemic. It brought me a self-awareness of the real threat to human life that the virus posed. I began to take extra hygiene precautions such as hand sanitizing a bit more, washing my mask daily, and moving away from gatherings and invitations to small social functions.
Stephanus was an Afrikaans man in his mid-30s living alone in the city. He had made an appointment to see me during the early days of lockdown because he felt anxious about getting sick with the coronavirus. He described a daily routine that reflected an obsessive mannerism of constant handwashing, sanitizing surfaces in the house not just a few times but many times a day, as well as washing down all his groceries, which were ordered online and delivered to him. He never left the house except to seek medical attention or visit the dentist. He scanned all the newspapers and news channels for information about COVID-19 and he knew the daily new number of confirmed cases. He made contact with friends and family via Zoom or WhatsApp. He preferred to be alone. At one point he fired is maid so she would not come to the house. He confessed that he felt she could infect him as she lived in close proximity to a large family and within an over-crowed community in the townships. His sessions were filled with anxious stories of getting ill, of other people getting ill, and of the daily news of COVID-19. After a few sessions with the same kind of stories, I began to notice my boredom, which spilled over into a dread for our sessions. Perhaps I was defending against some inner story of getting ill but Stephanus was my boring patient. But all stories have meaning, and all patients, boring ones as well, have something to say. I told myself to listen harder.

About two months into lockdown, when restrictions were still severe, and the confirmed case of coronavirus increased daily, Stephanus told the story of how his mother had died when he was a young boy. She had been ill for a long time, perhaps months, and he remembered she was in and out of hospital. His father, a strict authoritarian man had ordered the household servants to clean the house every time the mother went away to hospital. He realized as a boy that it was the father who wanted a germ-free household which would ensure that he or his father did not get ill. The father would also order little Stephanus to wash his hands regularly and bath every day. One day the father said to him that if he missed washing his hands on a regular basis, his mother would die. Frightened and fearing his father's dire warnings, young Stephanus, an only child, became obsessed with cleanliness. On the day his mother died, he tried to recall if he had washed his hands enough that day. When the father returned from the hospital with the news of her death, little Stephanus believed that his mother had died because he had not washed his hands enough.

It is not difficult to make the connection between this story of his childhood story drenched in obsessive cleaning and hand washing to prevent the death of a beloved mother, and the adult man who feared getting ill and washed his hands and cleaned the house many times a day. I heard the story now, no longer masked by my counter-transference of boredom. Stephanus was no longer my boring patient. In the shadow of COVID-19 and the threats it held to his health, Stephanus was living 
in the shadows of a past that was repeating itself in the present. The pandemic, with its lack of a vaccine, had brought up dreadful and unspoken memories of a father insisting on rituals of cleanliness that would, in their minds, prevent the death of the mother. The stories of cleaning and fearing contracting COVID-19 made sense to me. In my mind I was never afraid of contracting the virus. My thoughts about it were that most people who became infected recovered especially if they had no comorbidities. I also felt that the washing of hands or hand sanitizing was appropriate but that I need not do it so many times a day.

His stories of childhood and his stories of adulthood of obsessive cleanliness to fight against an unseen enemy virus impacted on me in a deep and meaningful way. I realized that although I was not as fearful as Stephanus, I recognized that I was defending against not so much as getting ill with the virus but with infecting my partner. In this context, the tale of his childhood belief that he killed his mother, was a warning to me that while I may get infected at some point and yet also survive and recover, my partner may not survive as he has comorbidities. To this extent, I may also kill the very person I love.

\section{Comment on the stories that describe difficult experiences of the impact of COVID-19}

Since Freud's writings and into the development of contemporary relational psychoanalytic theory, remains the core concept that unprocessed experience remains repressed within the psyche only to replicate itself unconsciously in some form in the present moment. Stephanus told the tale of childhood memories that had remain unheard and unspoken. As a child, he had believed he was responsible for the death of his mother because he had not washed his hands enough. This story had played out unconsciously within his psyche, like an old tape recorder, when the COVID-19 pandemic emerged. While sobering and unsettling, his story reminded me about unconscious dynamics within myself and to be more cautious and use the preventative measures available against this pandemic, lest I kill that which I love. Katlego's story of loss and pain impact on me because it recalled to my mind the utter vulnerability of life in the face of Covd-19. We are all defenseless without a cure against this dragon-monster of a virus that threatens life.

My inner story is shaped by Katlego and Stephanus and their stories of COVID-19. Stories like these are stories of the unbearable. Hearing these unbearable stories gives meaning to them, gives a voice to them, and thus gives a spark of healing. Without the story first told within oneself, and then told to another, the story remains disconnected and frozen, without a beginning or an ending. It has been written that without the creation of a story first told within oneself and only transformative when told to another - catastrophe will produce only the doodling of sound which is the desperate seeking of language, con- nectiveness, and story before the silence of psychosis or psychic death is complete (Bion, 1963; cited in Abbott, 2011). The harder to hear stories are stories of creating $a$ language to suffering, and thus a collective connectivity bonded by suffering - for who can remain separate, untouched, uninvolved from human suffering caused by COVID-19? The harder to hear stories of suffering - because they are told - fight off, for a while, the silent threat of madness and psychosis.

\section{Final comments}

This paper set out to describe my story as shaped by my response to hearing the stories of my patients of their experience of the impact of the COVID-19 pandemic. In writing this paper and documenting my story or storiedcounter-transference, I found myself wondering about the harder to hear stories of my patients. As a therapist, I have been exposed to many difficult to bear stories that they tell. The stories of Katlego and Stephanus are examples of these harder to hear stories. The trauma they have experienced as a result of COVID-19 shattered their world. To some extent, there is a dissociated horror. Their stories sit with me and stir up some old untold stories within me. The good stories, on the other hand, told by my patients of their good experiences of the impact of COVID-19, are like sunshine after a stormy day. They make what is unbearable bearable. Aaron's stories are uplifting, a reminder of the human spirit's capacity to transcend uncertainty and horror. Abbott (2011) sums up this link between the good and harder to hear stories when he writes, "The joyful story comes as a rainbow for our tears; as a balm in our lamentations; as a dream of forever love in the face of surrounding death. The good memories - long gone into the hiddenness of the unconscious - are given rebirth when the unbearable experiences become driven out or forgiven" (Abbott, 2011, p. 93).

A final comment refers to my overall counter-transference in relation to the three stories. These three stories or cases are linked together through the threads of COVID-19. They show the diverse and diversity of the impact of the pandemic. To this end, as mentioned earlier by Benjamin (2009) "I can hear both your voice and mine as can you without one cancelling the other out; I can hear more than one part of yourself, you can hear more than one part of yourself ... It is now possible to recognize the presence of multiple voices and parts of self' (p. 442). This statement assisted me to make sense of my own reactions in that I heard their voices, and they heard mine too, and each time voices were heard, they did not cancel each other out. I could hear more than just the negative aspects of this pandemic in these three voiced stories. The notion that 'I change you, you change me' means that my reactions to my patients' stories really did change my own inner stories. 


\section{References}

Abbott, C. (2011). Seeking lost souls and exorcising demons: Christological co-narration in psychoanalytic storytelling. Journal of Spirituality in Mental Health, 13, 92-137. doi: 10.1080/19349637.2011.565237

Aron, L. (1996). A meeting of minds: Mutuality in psychoanalysis. Hillsdale, NJ: The Analytic Press.

Atlas, G., \& Aron, L. (2018). Dramatic dialogue: Contemporary clinical practice. New York, NY: Routledge.

Benjamin, J. (2009). A relational psychoanalysis perspective on the necessity of acknowledging failure in order to restore the facilitating and containing features of the intersubjective relationship (the shared third). International Journal of Psychoanalysis, 90, 441-450. doi: 10.1111/j.1745-8315.2009. 00163.x

Benjamin, J. (2018). Beyond doer and done to: Recognition, intersubjectivity, and the third. New York: Routledge.
Bion, W. (1963). Elemental psycho-analysis. London, England: Heineman.

Cooper, S. (2012). Exploring a patient's shift from relative silence to verbal expression. International Journal of Psychoanalysis, 93, 897-916.

Geist, R. A. (2013). How the empathic process heals: A microprocess perspective. International Journal of Psychoanalytic Self Psychology, 8(3), 265-281. doi: 10.1080/15551024. 2013.800357

Kohut, H. (1959). Introspection, empathy, and psychoanalysis. Journal of American Psychoanalysis Association, 7, 459483.

Mitchell, S. A. (2000). Relationality: From attachment to intersubjectivity. Hillsdale, NJ: Analytic Press.

Ogden, T. (1994). Subjects of analysis. Northvale, NJ: Aronson.

Parsons, M. (2006). The analyst's countertransference to the psychoanalytic process. International Journal of Psychoanalysis, 87, 1183-98. 